\title{
Imaging of Multiple Myeloma and Related Plasma Cell Dyscrasias
}

\author{
Ronald C. Walker ${ }^{1,2}$, Tracy L. Brown ${ }^{3}$, Laurie B. Jones-Jackson², Lorraine De Blanche ${ }^{3}$, and Twyla Bartel ${ }^{3}$ \\ ${ }^{1}$ Medical Imaging Department, Tennessee Valley VA Healthcare System, Nashville, Tennessee; ${ }^{2}$ Department of Radiology and \\ Radiological Sciences, Vanderbilt University Medical Center, Nashville, Tennessee; and ${ }^{3}$ University of Arkansas for Medical \\ Sciences, Department of Radiology, Little Rock, Arkansas
}

\begin{abstract}
Learning Objectives: On successful completion of this activity, participants should be able to describe (1) the benefits and limitations of both conventional and advanced imaging in evaluating patients with multiple myeloma and related plasma cell dyscrasias; (2) imaging findings of key significance for clinical management of patients with multiple myeloma and related plasma cell dyscrasias; and (3) common and sometimes life-threatening complications of myeloma and its treatment.
\end{abstract}

Financial Disclosure: The authors of this article have indicated no relevant relationships that could be perceived as a real or apparent conflict of interest.

CME Credit: SNM is accredited by the Accreditation Council for Continuing Medical Education (ACCME) to sponsor continuing education for physicians. SNM designates each JNM continuing education article for a maximum of 2.0 AMA PRA Category 1 Credit. Physicians should claim only credit commensurate with the extent of their participation in the activity.

For CE credit, participants can access this activity through the SNM Web site (http://www.snm.org/ce_online) through July 2013.

Multiple myeloma (MM) is an incurable plasma cell malignancy of the bone marrow. MM has 3 components: diffuse marrow infiltration, focal bone lesions, and soft-tissue (extramedullary) disease. The hallmark biomarker in blood or urine is a monoclonal immunoglobulin, the monoclonal protein. Waldenstrom macroglobulinemia is a similar disease with secretion of lgM. Staging is classically performed with the 1975 Durie-Salmon system, which includes conventional radiographs. Recently updated, the DurieSalmon Plus staging system includes CT, MRI, and ${ }^{18} \mathrm{~F}-\mathrm{FDG}$ $\mathrm{PET} / \mathrm{CT}$. The hallmark radiographic lesion of symptomatic MM is a well-demarcated, focal osteolytic bone lesion. The number of focal bone lesions correlates inversely with outcome. Extramedullary disease is typically an aggressive, poorly differentiated form of MM that confers inferior outcome, with median survival of less than $1 \mathrm{y}$ if present at diagnosis. Achievement of a complete response on ${ }^{18} \mathrm{~F}-\mathrm{FDG}$ PET before stem-cell transplantation correlates with a superior outcome.

Key Words: MRI; multiple myeloma; PET/CT; POEMS syndrome; solitary plasmacytoma

J Nucl Med 2012; 53:1091-1101

DOI: 10.2967/jnumed.111.098830

\section{$\mathbf{M}$} ultiple myeloma (MM) is an incurable malignancy characterized by clonal proliferation of plasma cells in the bone marrow microenvironment. MM is typically charac-

Received Apr. 5, 2012; revision accepted May 31, 2012.

For correspondence or reprints contact: Ronald C. Walker, Tennessee Valley VA Healthcare and Vanderbilt University Medical Center, CCC-1121 MCN, 116121 st Ave. S., Nashville, TN 37232-2675.

E-mail: ronald.walker@vanderbilt.edu

Published online Jun. 12, 2012.

COPYRIGHT ( 2012 by the Society of Nuclear Medicine, Inc. terized by secretion of a monoclonal protein (M-protein), detected in the blood or urine, and by associated end organ disease, including the hallmark sharply defined lytic bone lesions present in $85 \%$ of patients with MM. MM typically evolves from an asymptomatic, premalignant condition called monoclonal gammopathy of undetermined significance (MGUS), with M-protein detected in blood or urine in a multistep process involving complex genetic mutations and bone marrow microenvironmental interactions. There is no end organ damage in MGUS or in a more progressed condition called smoldering MM. Accordingly, MGUS and smoldering MM are usually not treated, but there are investigational chemoprevention trials attempting to halt the progression to symptomatic MM. In smoldering MM, bone marrow biopsy shows a $10 \%-60 \%$ diffuse infiltration of plasma cells, and the infiltration is less than $10 \%$ in MGUS. Although MM can arise de novo, it usually progresses in a stepwise fashion from MGUS or smoldering MM. If marrow infiltration with plasma cells exceeds $60 \%$, or if end organ damage is present, the patient is diagnosed with active MM $(1,2)$.

$\mathrm{MM}$ is the second most common hematologic malignancy, representing $1 \%$ of all cancers and $13 \%$ of hematologic malignancies. In Western countries, the annual incidence is 5.6 cases $/ 100,000$ people. Median age at diagnosis is $70 \mathrm{y}$, with $37 \%$ younger than $65 \mathrm{y}$ and $37 \%$ $75 \mathrm{y}$ old or older. In recent years, with a combination of autologous stem-cell transplantation and modern chemotherapy, the $10-y$ survival of patients presenting at an age less than $60 \mathrm{y}$ is approximately $30 \%(1,2)$.

Imaging of MM and related diseases includes anatomybased modalities (conventional radiography and CT), conventional or whole-body MRI, and functional imaging 
(PET/CT or ${ }^{99 \mathrm{~m}}$ Tc-sestimibi imaging (3)). The whole-body radiographic series is the metastatic bone survey (MBS). Clinical imaging of MM and related diseases with PET/ CT uses ${ }^{18}$ F-labeled FDG, with other PET radiopharmaceuticals still investigational. ${ }^{99 \mathrm{~m}} \mathrm{Tc}$-sestimibi imaging using planar imaging, SPECT, or SPECT/CT is useful, particularly when ${ }^{18} \mathrm{~F}-\mathrm{FDG}$ PET/CT is not available (4-6). The classic imaging finding in $\mathrm{MM}$ is one or more focal osteolytic lesions seen on radiographs (Fig. 1) or CT, but there is also a systemic bone loss leading to diffuse osteopenia or osteoporosis $(7,8)$.

MM bone loss is due to complex interactions between the tumor and the bone marrow microenvironment leading to both osteoclastic stimulation and inhibition of osteoblastic function. This tumor-induced diffuse bone loss compounds the treatment-induced bone loss from frequent use of highdose glucocorticoid medications (typically dexamethasone), leading to severe osteoporosis. Much of the morbidity in $\mathrm{MM}$ results from insufficiency fractures from the profound bone loss seen in MM. Because the dickkopf 1 protein secreted by MM destroys the osteoblast progenitors (Fig. 2), focal osteolytic bone lesions from MM never heal $(7,9)$.

Diffuse marrow infiltration with plasma cells in MM is often accompanied by focal lesions, with or without focal osteolysis. Active focal lesions of MM are well-circumscribed areas of increased uptake on PET or abnormal signal on MRI that an experienced imaging provider interprets as most likely to represent tumor. To avoid excessive false-positives, a finding must be at least $5 \mathrm{~mm}$ in diameter to be considered a focal lesion (10).

A minority of patients at diagnosis will have normal imaging findings. The presence of one or more focal lesions with $10 \%$ or greater plasma cell marrow infiltration establishes symptomatic MM. More than one skeletal focal lesion without marrow infiltration identifies a variant of MM called multiple solitary plasmacytomas, in which image-guided biopsy of focal lesions is key to diagnosis (11-14).

About $5 \%$ of patients at presentation are thought to have solitary plasmacytoma of soft tissue or bone, though many are actually under-staged MM patients. Central marrow biopsy or additional imaging with MRI or ${ }^{18}$ F-FDG PET/ CT will often demonstrate additional sites of tumor, leading to a correct diagnosis. Correct diagnosis is essential for proper treatment since patients with a solitary lesion seldom require systemic treatment (14-20).

FIGURE 1. Stable focal osteolytic bone lesions of skull and right humerus in a patient with $\mathrm{MM}$ in complete remission for $5 \mathrm{y}$. Lateral skull (left) and humeral shaft (right) radiographs of the patient demonstrate multiple focal osteolytic lesions (some with arrows) that will never heal even if patient remains in complete remission for many years.
The number of focal lesions at baseline on radiographs, MRI, or ${ }^{18}$ F-FDG PET/CT is a key finding, inversely and significantly related to both overall and event-free survival (21). The number of focal lesions at baseline on MRI is also inversely and significantly related to event-free survival but not to overall survival (10). The adverse impact on patients of the number of focal lesions at baseline ( 3 or more on ${ }^{18} \mathrm{~F}$ FDG PET/CT and 7 or more on MRI) is second only to the presence of high-risk disease as identified by gene expression profiling (Fig. 3) (10,21).

Imaging reports for $\mathrm{MM}$ should include the number of MRI or PET focal lesions and the presence and approximate number of $\mathrm{x}$-ray focal osteolytic lesions seen on the CT portion of PET/CT (some patients have too many focal lesions to accurately quantify). Untreated MRI or PET focal lesions will result in focal osteolytic bone lesions. PET/CT is superior to PET-only imaging (Fig. 4) because of the direct anatomic correlation that PET/CT provides for an area of focal ${ }^{18}$ F-FDG uptake $(10,22,23)$. Though an increase in focal lesion size indicates progression of disease, it is the number of focal lesions on MRI or PET, not the size, that correlates inversely with patient outcome. Perhaps the number of focal lesions is a surrogate for tumor heterogeneity and thus is related to the risk for the development of treatment resistance $(24,25)$. Discordant MRI and PET/CT results must be investigated (26). Direct comparison of current examinations to prior examinations is required because the number of focal lesions can remain the same or even

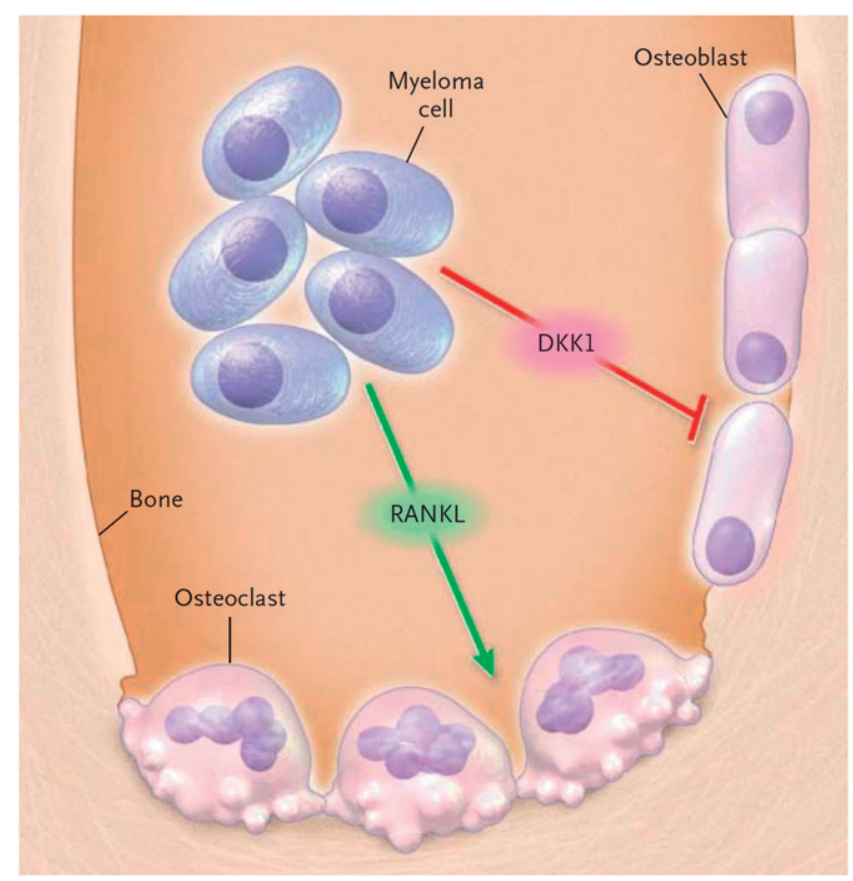

FIGURE 2. Dual mechanisms of bone loss in MM. Myeloma cells release RANK ligand (RANKL), stimulating osteoclasts, and dickkopf 1 (DKK1), a protein that inhibits osteoblastic function and leads to loss of osteoblastic differentiation and destruction of osteoblastlineage stem cells, resulting in lytic bone lesions that cannot heal. (Reprinted with permission of (9).) 


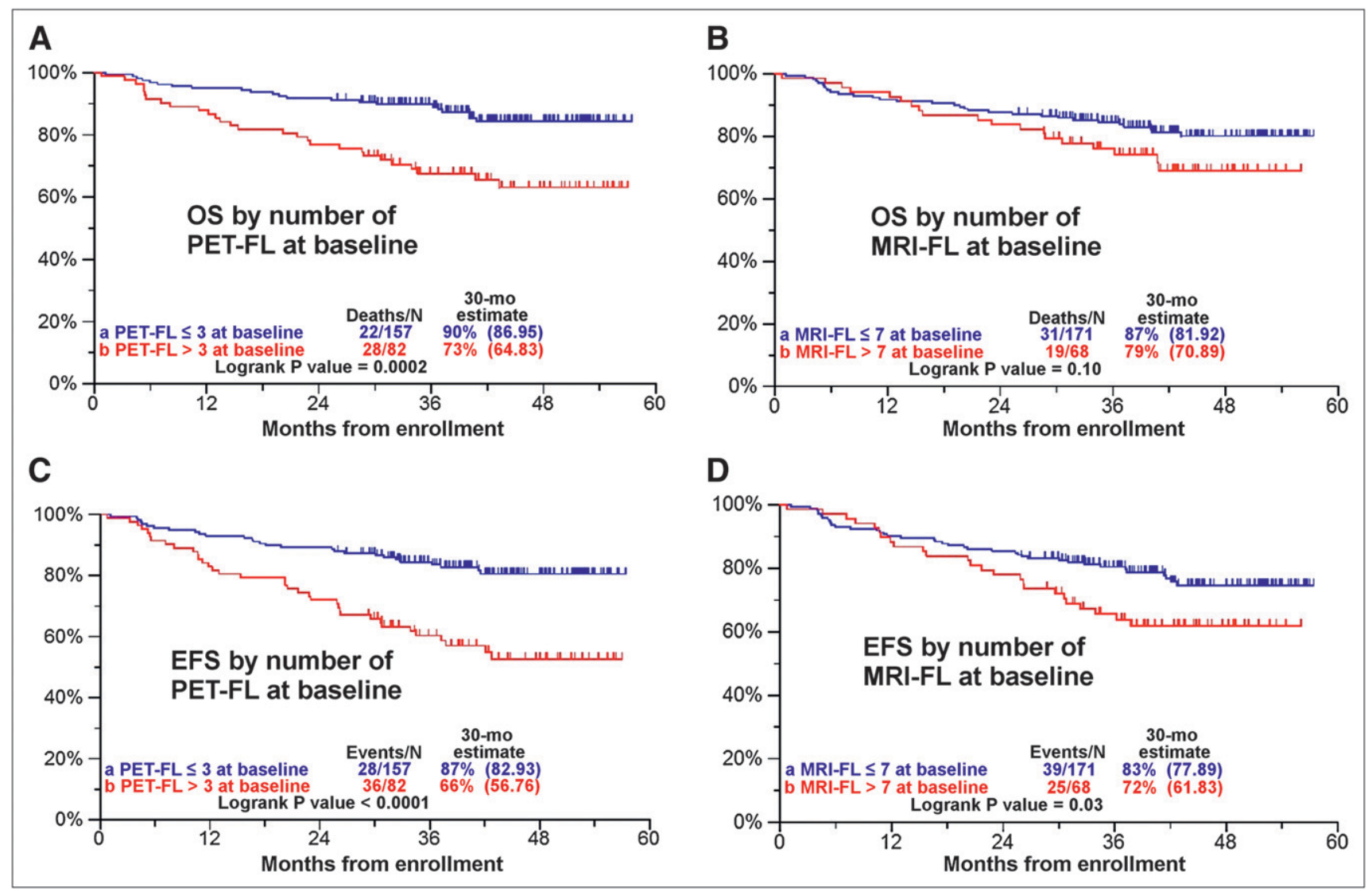

FIGURE 3. Kaplan-Meier analysis of significance of number of PET focal lesions and MRI focal lesions at baseline on overall survival (OS) and event-free survival (EFS). Three or more PET focal lesions (PET-FL) at baseline staging significantly impact OS (A) and EFS (C). On MRI, 7 or more focal lesions (MRI-FL) at baseline staging significantly impact EFS (D) but not OS (B). These data are derived from clinical trial Total Therapy 3. Number of focal lesions for analysis of PET vs. MRI was chosen for greatest significance. (Reprinted with permission from (21).)

decrease and yet new focal lesions can develop, identifying progression or relapse.

When tumor progression or relapse on MRI or PET/CT is suspected, standard laboratory evidence is usually supportive and no further verification is required. Restaging of patients with ${ }^{18} \mathrm{~F}-\mathrm{FDG}$ PET/CT is best done 2 and preferably 4 or more weeks after treatment cycle completion. However, if progression or relapse while on treatment is suspected, ${ }^{18} \mathrm{~F}-\mathrm{FDG}$ PET/CT can often provide verification and direction for biopsy or change in treatment $(27-30)$.

\section{EXTRAMEDULLARY DISEASE (EMD)}

Identification of EMD, tumor growing exclusively in the soft tissues independent of the bone marrow, is vital because its presence identifies a patient at high risk compared with similar-stage patients without EMD. EMD represents an MM entity that is typically poorly differentiated, often nonsecretory, rapidly progressive, and treatment-resistant. Because many MM treatments target the MM-bone marrow microenvironment interaction, these treatments will be ineffective in treating EMD. Median survival for relapsing or refractory patients with EMD at baseline is less than $1 \mathrm{y}$.
It is important to differentiate between breakout lesions and true EMD. Breakout lesions are regions where the tumor has broken through the cortex into the surrounding soft tissues, but with the tumor still in contact with and dependent on the tumor-bone marrow interactions. Both EMD and breakout lesions can be detected with MRI, PET/CT, or ${ }^{99 \mathrm{~m} T c-s e s t i m i b i}$ imaging. PET/CT and ${ }^{99 \mathrm{~m} T c-}$ sestimibi are superior to MRI because of their wider, wholebody fields of view compared with conventional MRI examination, though whole-body MRI may be of equal efficacy. EMD (Fig. 5) develops with increasing frequency with the duration of the disease $(3,10,21,31-33)$.

\section{HYPOSECRETORY AND NONSECRETORY DISEASE}

Most patients with MM demonstrate secretion of the hallmark M-protein. However, in $1 \%-5 \%$ of patients at diagnosis, disease is classified as hypo- or nonsecretory, with no or very low levels of M-protein detected $(34,35)$. Most of these patients will have elevated levels of $\kappa$ or $\lambda$ free light chains (light chain fragments of immunoglobulins). When patients with M-protein or elevated free light chains are excluded, less than $1 \%$ of MM patients are truly nonsecretory at diagnosis $(35,36)$. In these nonsecretory 
A

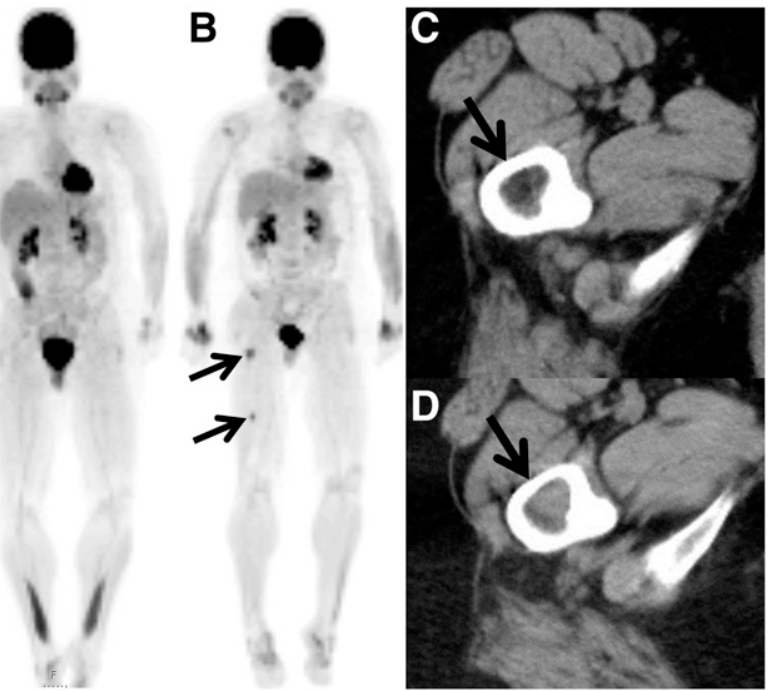

FIGURE 4. ${ }^{18} \mathrm{~F}-\mathrm{FDG}$ PET/CT detects progression of MGUS to MM. Anterior 3-dimensional maximum-intensity-projection images performed at time of diagnosis of MGUS (A) and 30 mo later (B) demonstrate progression to MM, with 2 PET focal lesions (arrows) representing intramedullary lesions without corresponding radiographic lytic lesion and thus invisible by MBS. Axial CT portion of $\mathrm{PET} / \mathrm{CT}$ through upper right femur at level of superior lesion at baseline (C) shows normal fatty marrow; at 30-mo follow-up (D), focal intramedullary plasmacytoma nodule is visible (arrows).

patients, measuring treatment response is difficult because serial M-protein or free light chain levels cannot be followed. The percentage of patients with nonsecretory disease increases with the duration of survival and, when observed, typically reflects dedifferentiation of the tumor to a more aggressive form. In nonsecretory patients, imaging with ${ }^{18} \mathrm{~F}$-FDG PET/CT is particularly useful for monitoring disease status and treatment response. MRI is also useful in this setting for detection of relapse or progression but not treatment response $(10,37-40)$.

\section{OSTEOSCLEROTIC MYELOMA}

POEMS syndrome (polyneuropathy, organomegaly, endocrinopathy, presence of $\mathrm{M}$ protein, and skin changes) is a rare, poorly understood MM variant that demonstrates osteosclerotic changes that can be diffuse or focal. Accordingly, POEMS syndrome is also called osteosclerotic myeloma (41-44). Although the diagnosis of POEMS syndrome is complex, diffuse or focal osteosclerotic bone lesions in the proper clinical setting should suggest the diagnosis (Fig. 6). Occasionally, diffuse osteosclerotic changes occur with focal osteolytic lesions. POEMS syndrome patients have a superior median survival compared with classic MM patients.

\section{INFORMATION TO BE REPORTED ON IMAGING STUDIES}

There are key findings directly relevant to clinical care that must be reported when imaging MM and related diseases.

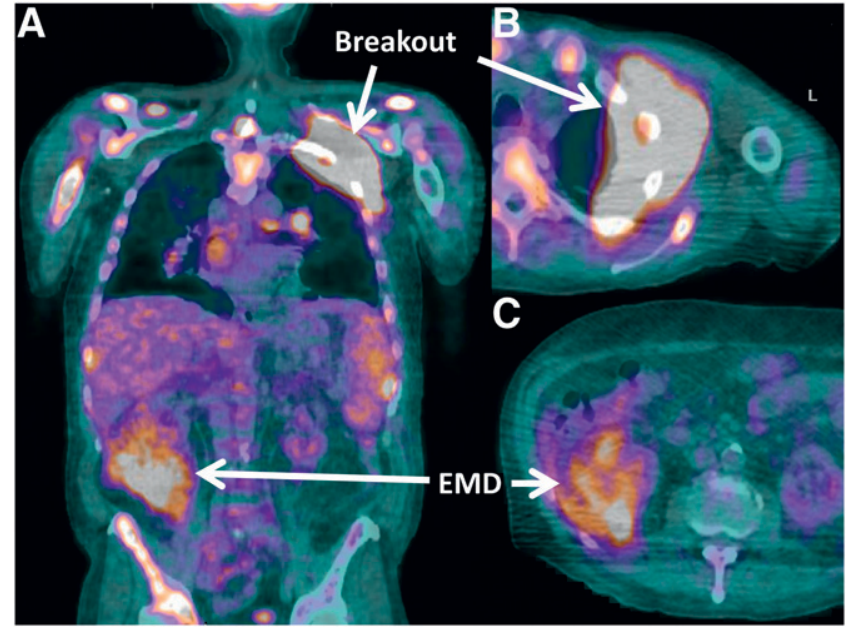

FIGURE 5. Breakout vs. EMD. Fused coronal (A) and axial (B and C) ${ }^{18} \mathrm{~F}-\mathrm{FDG} \mathrm{PET} / \mathrm{CT}$ images in patient with advanced MM demonstrate a breakout lesion in the upper left chest, arising from the upper left rib, still in contact with and dependent on the bone marrow microenvironment. The right perinephric area demonstrates a focus of biopsy-proven, exclusively soft-tissue, MM (true EMD).

In accordance with the new Durie-Salmon Plus staging, identification and quantification of the number and size of focal skeletal lesions seen on MRI, MBS, or ${ }^{18} \mathrm{~F}-\mathrm{FDG}$ PET/ CT should be reported. This allows for risk stratification based on the number of focal lesions found by MRI or ${ }^{18} \mathrm{~F}-\mathrm{FDG}$ PET/CT at baseline and restaging (10,21), determination of whether a focal lesion on MRI corresponds via radiography or CT with an area of focal osteolysis (if not, effective treatment can prevent this irreversible end organ damage), detection of EMD (21), and identification of areas for safe or high-yield biopsies, such as the site of greatest uptake on ${ }^{18} \mathrm{~F}-\mathrm{FDG}$, EMD, or otherwise dominant lesions $(10,11)$.
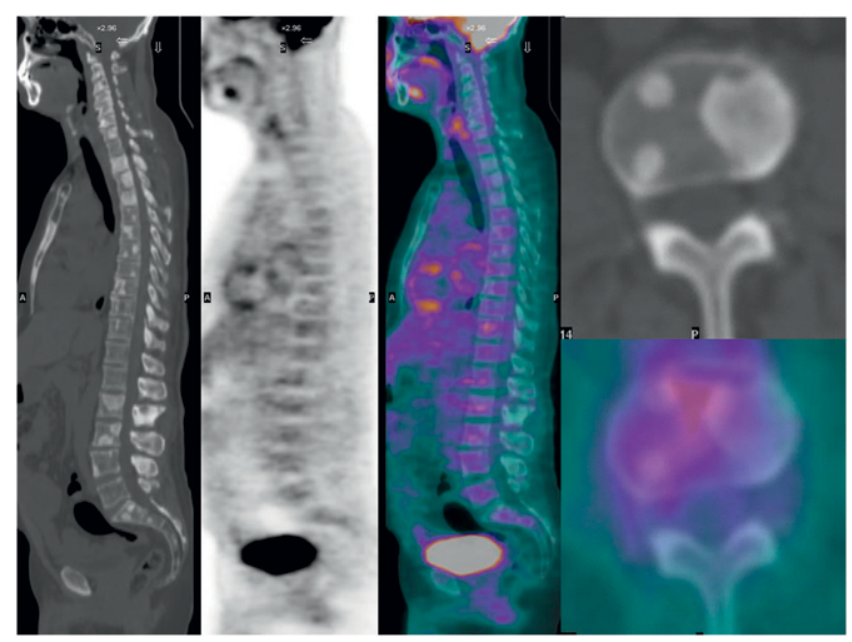

FIGURE 6. POEMS syndrome as seen on ${ }^{18} \mathrm{~F}-\mathrm{FDG}$ PET/CT. From left to right are shown sagittal CT, emission PET, fused PET/CT, and axial CT (top) and fused PET/CT (bottom) of patient with laboratory and marrow biopsy evidence of MM but with focal osteosclerotic bone lesions. 
Also to be reported are any areas identified as being at high risk for pathologic fractures, allowing possible preemptive action (e.g., vertebroplasty, surgical intervention, or focal radiation therapy), and any treatment-related complications such as avascular necrosis or possible osteonecrosis of the mandible or maxilla $(45,46)$.

Any diffuse marrow infiltration seen on MRI or ${ }^{18} \mathrm{~F}$-FDG PET/CT should be reported $(10,21)$, along with any highrisk areas of tumor that may need immediate aggressive treatment (e.g., epidural tumor endangering the spinal cord or a lytic lesion of the odontoid process) (3), any occult infection detected (47-50), and any important but previously unsuspected comorbid conditions, such as additional primary malignancies or premalignant colon polyps (51).

\section{MBS}

The classic Durie-Salmon staging system of MM at baseline and restaging was established in 1975 (52). Recently, Durie developed the Durie-Salmon Plus system (Table 1), including advances in imaging technology developed since $1975(37,53)$.

The MBS remains in widespread use, consisting of plain radiographs of the entire skeleton. Although sensitive in the skull and extremities, the MBS is less sensitive for detecting focal lesions in the more central skeleton because of mixed densities from overlapping bones, air, solid organs, and gut contents that can either simulate or obscure focal bone lesions. Cadaveric studies have shown that at least $50 \%$ of focal loss of bone in a vertebral body must occur for a lytic lesion to be seen on a radiograph (Fig. 7) (54). Importantly, MBS cannot detect intramedullary tumor that has not produced a radiographic finding. MBS is limited in the ability to detect EMD. Osteoporosis and osteopenia are late findings on MBS. Although MBS cannot demonstrate a response to treatment, it can reveal relapse or progression if new focal bone lesions appear. MBS is useful when MRI or PET/CT is limited by artifacts, such as from orthopedic hardware. MBS may also reveal unsuspected findings, such as infection or other malignancies $(21,55)$.

\section{CORRELATING ${ }^{18}$ F-FDG PET/CT AND MRI OF MM}

MRI is well established for imaging of MM and related diseases, having been used for the staging and restaging of MM since the 1980s. Though more expensive, MRI is more widely available than ${ }^{18} \mathrm{~F}-\mathrm{FDG}$ PET/CT and does not expose the patient to ionizing radiation. Accordingly, nuclear medicine physicians will frequently need to correlate MRI examinations with ${ }^{18} \mathrm{~F}-\mathrm{FDG}$ PET/CT in MM patients. In the MRI protocol for MM, the region of most common tumor involvement, the adult hematopoietic marrow, is imaged. Specific protocols vary between manufacturers and according to the specific scanner, available coils, and other factors. With effective treatment, the marrow signal returns to normal. The diffuse marrow infiltration can normalize in near real time. Focal lesions gradually fill in with scar tissue with low water content, matching the MRI signal of normal central marrow if the patient remains in remission. The normalization of MRI focal lesions can take weeks to years, depending on the size of the focal bone lesion (56-65). Knowledge of the normal appearance of the central marrow for the patient's age is a prerequisite for proper interpretation of the MR image. The use of marrow-stimulating medications and chemotherapy rebound will cause changes in the marrow MRI signal resembling diffuse MM infiltration. These hypercellular marrow changes are also seen on PET/CT or ${ }^{99 \mathrm{~m} T c-s e s t i m i b i}$ as diffuse, intense radiopharmaceutical uptake in the marrow $(3,10)$.

MRI-defined focal lesions (Fig. 8) can be obscured by either intense diffuse marrow infiltration from tumor or by marrow stimulation or chemotherapy rebound. Because the diffuse infiltration responds more quickly to effective treatment than the focal lesions, underlying MRI focal lesions can become visible as the diffuse cellular infiltration subsides. This clearing of the diffuse marrow infiltration that reveals underlying, persistent MRI focal lesions (Fig. 9) is termed unmasking and should not be confused with progression on treatment (10).

TABLE 1

Durie-Salmon Plus Staging System

\begin{tabular}{|c|c|c|}
\hline Classification & Plus & New MRI or ${ }^{18} \mathrm{~F}$-FDG PET \\
\hline MGUS & & All negative \\
\hline \multicolumn{3}{|l|}{ MM } \\
\hline $\begin{array}{l}\text { Stage IA } \\
\text { (smoldering or indolent) }\end{array}$ & $\begin{array}{l}\text { A: serum creatinine }<2.0 \mathrm{mg} / \mathrm{dL} \text { and no EMD; } \\
\text { B: serum creatinine }>2.0 \mathrm{mg} / \mathrm{dL} \text { or EMD }\end{array}$ & $\begin{array}{l}\text { Can have single focal } \\
\text { plasmacytoma or limited } \\
\text { disease on imaging }\end{array}$ \\
\hline Stage IB & $\begin{array}{l}\text { A: serum creatinine }<2.0 \mathrm{mg} / \mathrm{dL} \text { and no EMD; } \\
\text { B: serum creatinine }>2.0 \mathrm{mg} / \mathrm{dL} \text { or EMD }\end{array}$ & $\begin{array}{l}<5 \text { focal lesions; } \\
\quad \text { mild diffuse disease }\end{array}$ \\
\hline Stage IIA/B & $\begin{array}{l}\text { A: serum creatinine }<2.0 \mathrm{mg} / \mathrm{dL} \text { and no EMD; } \\
\text { B: serum creatinine }>2.0 \mathrm{mg} / \mathrm{dL} \text { or EMD }\end{array}$ & $\begin{array}{l}\text { 5-20 focal lesions; } \\
\text { moderate diffuse disease }\end{array}$ \\
\hline Stage III A/B & $\begin{array}{l}\text { A: serum creatinine }<2.0 \mathrm{mg} / \mathrm{dL} \text { and no EMD; } \\
\text { B: serum creatinine }>2.0 \mathrm{mg} / \mathrm{dL} \text { or EMD }\end{array}$ & $\begin{array}{l}>20 \text { focal lesions; } \\
\text { severe diffuse disease }\end{array}$ \\
\hline
\end{tabular}

Adapted with permission of (37). 


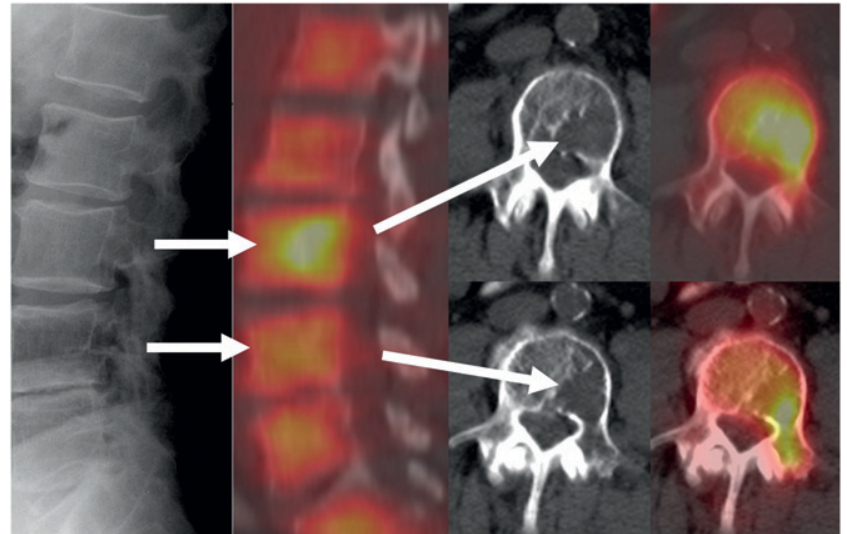

FIGURE 7. False-negative MBS. Focal osteolytic lesions of MM are seen well with ${ }^{18} \mathrm{~F}-\mathrm{FDG}$ PET/CT, compared with MBS. MBS lateral view of lumbar spine (far left) demonstrates no evidence of tumor. ${ }^{18} \mathrm{~F}-\mathrm{FDG}$ PET/CT (second from left) reveals diffuse myeloma marrow infiltration (shorter arrows) and focal lytic bone lesions (Ionger arrows) of L3 and L4. Axial ${ }^{18} \mathrm{~F}-\mathrm{FDG}$ PET/CT fused images are at far right, and corresponding CT-only images are second from right. (Reprinted with permission from (31).)

Additional MRI findings commonly seen in MM patients include insufficiency fractures, infections, avascular necrosis of the femoral or humeral heads, and osteonecrosis of the maxilla or mandible $(3,10,45,46,66)$.

Although MRI is extremely useful for staging and restaging of MM patients, it has limitations. Some patients cannot be imaged because of implanted devices (e.g., pacemakers or defibrillators). MR images can be limited by artifacts such as from orthopedic hardware, vertebroplasty cement, or cardiac or aortic pulsations. Because MRI often requires 45-90 min, motion artifacts often occur. An extensive MRI examination is typically more expensive than a whole-body PET/CT examination. Gadolinium must be used with caution in patients with renal impairment, common in MM patients, because of the risk of nephrogenic systemic fibrosis $(3,67,68)$.
A
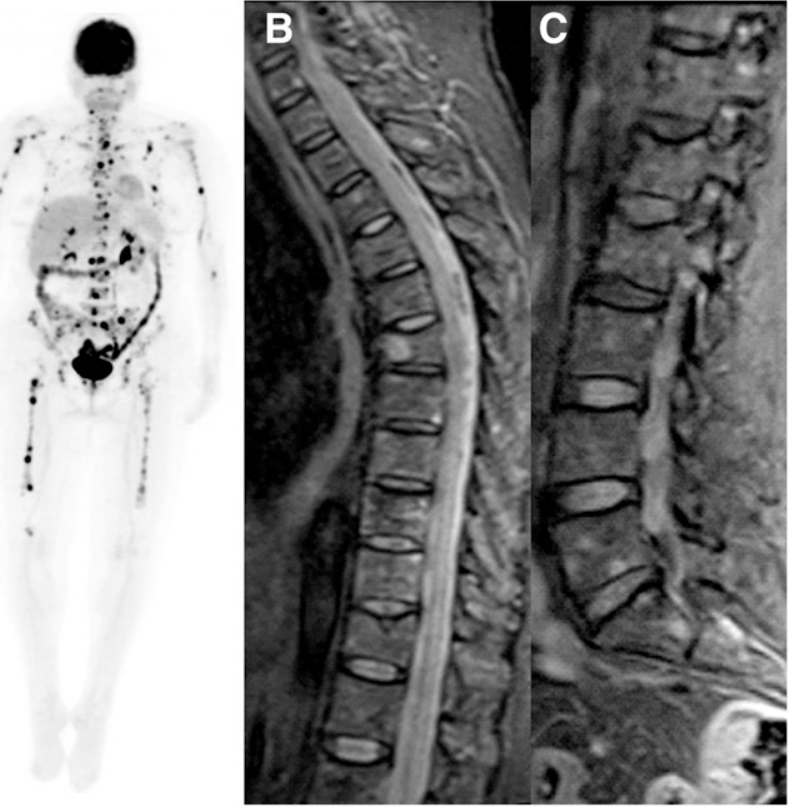

FIGURE 8. MM patient with innumerable focal lesions seen with $\mathrm{PET}$ and MRI. Anterior 3-dimensional maximum-intensity-projection ${ }^{18}$ F-FDG PET image (A) and sagittal short-tau inversion recovery images of thoracic (B) and lumbar (C) spine reveal innumerable focal lesions and partial compression fractures of upper-end plates of several vertebrae (e.g., L1 and L2).

The relative advantages of MRI over ${ }^{18} \mathrm{~F}$-FDG PET/CT are its superior spatial and contrast resolution-typically $2 \mathrm{~mm}$ for a 1.5-T MRI system versus approximately 5-8 $\mathrm{mm}$ for the PET portion of current PET/CT scanners. Also, MRI is more widely available. As with other malignancies, ${ }^{18} \mathrm{~F}-\mathrm{FDG}$ PET can be falsely negative in recently treated patients because of transient suppression of tumor metabolism, whereas MRI is not as limited in this setting. MRI is also superior to all other modalities, including PET/CT, for early diagnosis of avascular necrosis $(3,10,45)$.

FIGURE 9. Unmasking of MRI focal lesion. Sagittal short-tau inversion recovery MRI series at baseline (BL) and at restaging examinations, with indication of number of days relative to baseline. Baseline examination demonstrates diffuse, severely increased marrow signal from diffuse marrow infiltration. By 223 d, diffuse signal has improved, unmasking underlying focal lesions (arrows) because focal lesions respond more slowly to treatment. By $314 \mathrm{~d}$, diffuse marrow signal is normal, MRI focal lesions are slowly decreasing in size and intensity, and patient is in complete remission. By 1,867 d, patient is in durable remission, MRI finally appears normal, and MRI complete remission is finally achieved. (Reprinted with permission of (78).)

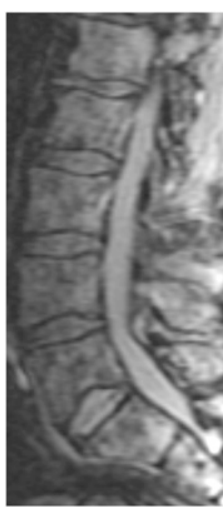

Baseline (BL)

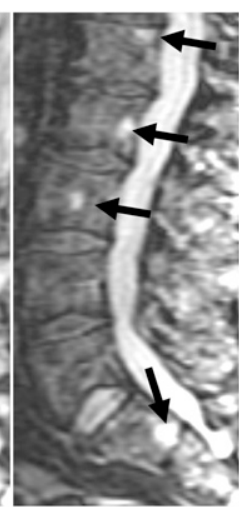

$B L+223 d$

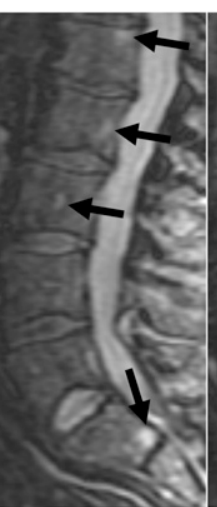

$B L+314 d$

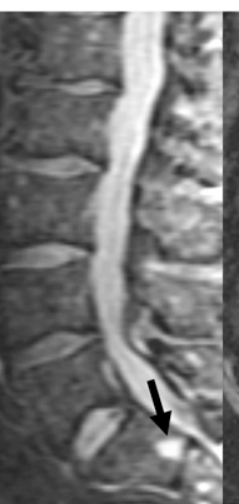

$B L+996 d$

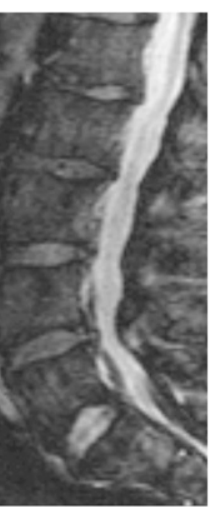

$B L+1,867 d$ 


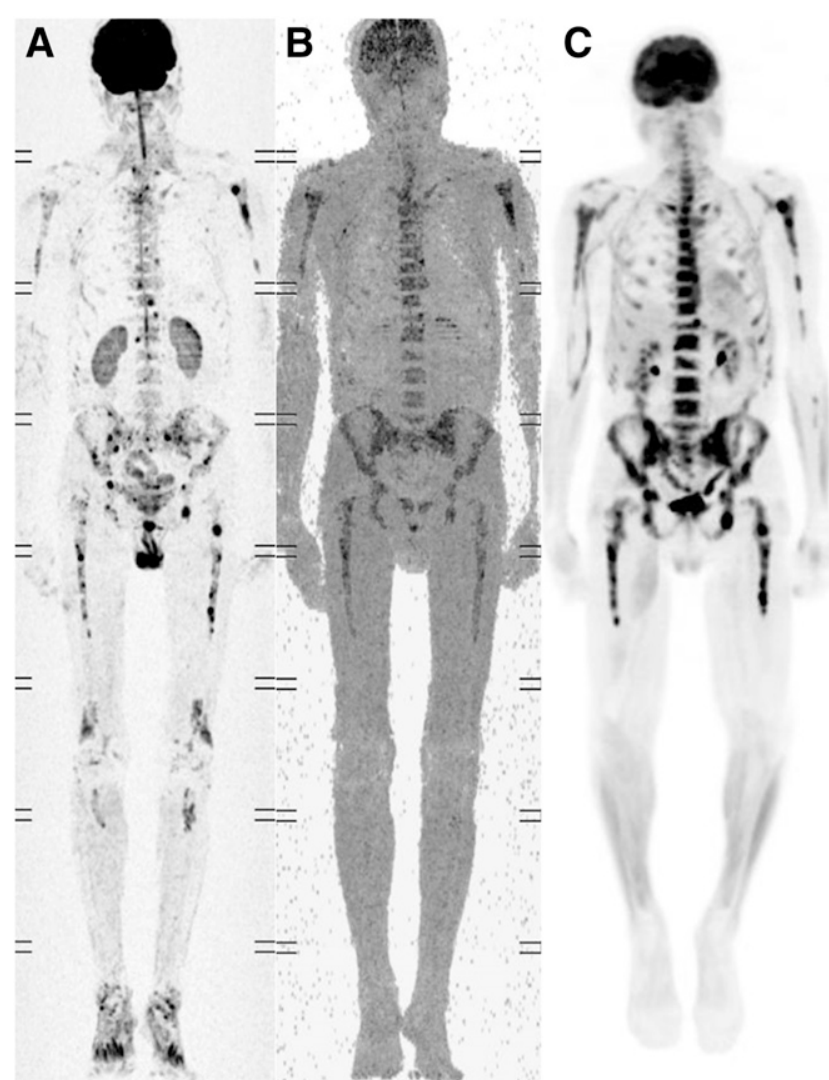

FIGURE 10. Baseline whole-body anterior MRI (A and B) and ${ }^{18} \mathrm{~F}-$ FDG (C) images of patient newly diagnosed with MM. MRI was performed using 3-dimensional maximum-intensity projection with diffusion weighting and restriction on apparent diffusion coefficient. All 3 images reveal severe diffuse and focal marrow infiltration.

Whole-body MRI (Figs. 10 and 11) is an emerging technology with an investigational role in the staging and restaging of MM and related diseases. Several reports have shown exquisite sensitivity for detection of bone marrow involvement in a variety of malignancies, including MM. Whole-body MRI has a field of view superior to that of conventional MRI, analogous to whole-body PET/CT. Whole-body MRI requires about 20-30 min to perform, comparable to whole-body PET/CT. It must be acquired separately from conventional MRI. The expense of wholebody MRI remains undefined since it is still investigational. Preliminary data suggest that response to treatment as seen on whole-body MRI occurs more rapidly than on conventional MRI but not as rapidly as on ${ }^{18} \mathrm{~F}-\mathrm{FDG}$ PET/ CT. Because whole-body MRI is based on the detection of stationary water, images are not tumor-specific and should be correlated with other imaging methods, such as CT or PET/CT. Whole-body MRI provides a possible future alternative to whole-body PET/CT if PET/CT is not available. As with conventional MRI, the patient is not exposed to ionizing radiation. Not all patients can undergo wholebody MRI due to pacemakers, aneurysm clips, or other devices (69-71).

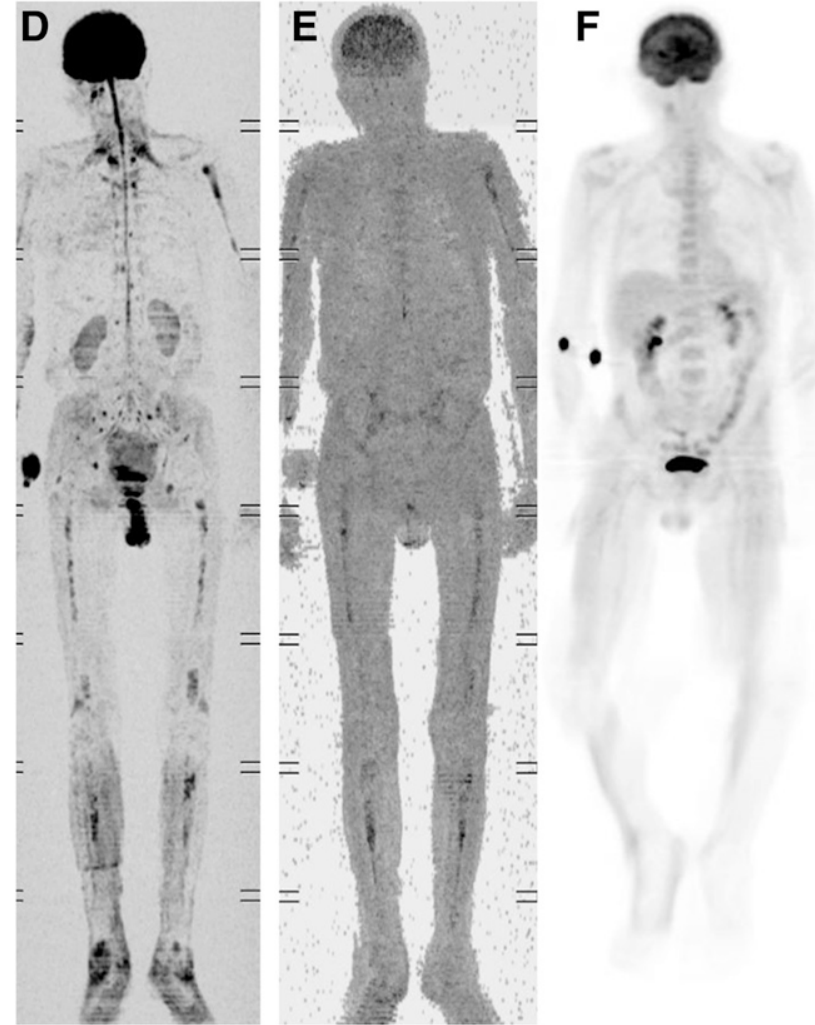

FIGURE 11. Treatment response seen on whole-body anterior MRI (C and E) vs. ${ }^{18} \mathrm{~F}-\mathrm{FDG}$ PET (F). Patient is same as shown in Figure 10. MRI was performed using 3-dimensional maximum-intensity projection with diffusion weighting and restriction on apparent diffusion coefficient. Improvement is seen on MRI, with some persistent abnormalities and normalization on PET. By tumor markers, patient was in remission, correlating best with PET image.

\section{9mTC-SESTIMIBI IMAGING}

${ }^{99 \mathrm{~m} T c-s e s t i m i b i ~ i m a g i n g ~ i s ~ u s e f u l ~ f o r ~ w h o l e-b o d y ~ i m a g-~}$ ing of MM. Because ${ }^{99 \mathrm{~m}} \mathrm{Tc}$-sestimibi uptake is normally relatively high in the myocardium, liver, and spleen and normally excreted in bile, visualization of MM is limited in these regions, but imaging with SPECT or SPECT/CT can improve the visualization of tumor in these regions, particularly in the abdomen. ${ }^{99 \mathrm{~m} T c-s e s t i m i b i}$ uptake is increased in active disease and normalizes in remission. The uptake of ${ }^{99 \mathrm{~m}} \mathrm{Tc}$-sestimibi can be falsely reduced in drug-resistant $\mathrm{MM}$, resulting in a false-negative scan. ${ }^{99 \mathrm{~m} T c-s e s t i m i b i}$ imaging is of proven utility in distinguishing MGUS from MM. ${ }^{99} \mathrm{~m} T c-s e s t i m i b i$ imaging is a good substitute when ${ }^{18} \mathrm{~F}$-FDG PET/CT is not available. ${ }^{99 \mathrm{~m} T c-}$ sestimibi imaging is also less expensive than PET/CT, is more widely available, and is not routinely needed in addition to ${ }^{18} \mathrm{~F}-\mathrm{FDG}$ PET/CT $(4,33,72-74)$.

\section{CLINICAL RELEVANCE OF IMAGING IN MM}

Imaging is essential for accurate staging and restaging of MM, with the updated Durie-Salmon Plus staging system incorporating advanced imaging. Imaging can greatly assist 
diagnosis by identifying high-yield sites for image-guided biopsies. Image guidance to focal lesions significantly increases the yield of clinically relevant cytogenetic abnormalities over random biopsies, improving early identification of patients with high-risk disease and assisting in the best selection of treatment $(11,75)$.

In the United States, the Centers for Medicare and Medicaid Services has approved broad-coverage reimbursement for imaging of MM with ${ }^{18} \mathrm{~F}-\mathrm{FDG}$ PET/CT for Medicare recipients at the time of "initial treatment strategy" (initial diagnosis and staging) and for additional PET/CT examinations performed for "subsequent treatment strategy" (restaging). Though still widely used, MBS has known limitations, with subtle changes in patient positioning sometimes simulating or obscuring focal lesions. Thus, excluding the upper skull and extremities, CT should be used to confirm any MBS-suspected finding or change $(10,21)$. Advanced imaging with MRI or PET/CT can detect intramedullary focal lesions before anatomic changes occur and can also detect the diffuse marrow infiltration component of MM. MBS will seldom detect EMD (21). Importantly, neither radiography- nor CT-based MBS can determine whether a given osteolytic lesion contains active disease (Fig. 12). Anatomic imaging is thus inferior to functional imaging for directing treatment or guiding biopsy.

Relapse and progression on treatment are readily detected with either MRI or PET, appearing as an increase in the size or number of focal skeletal lesions or sites of EMD. In relapse, the number of focal lesions can be fewer than, the same as, or more than that seen on earlier imaging studies (Fig. 13); thus, it is essential to correlate directly the new imaging study with previous imaging studies to determine whether a particular lesion is progressing or is new $(10,21)$.

High numbers of focal lesions on baseline examinations ( 3 or more on PET, 8 or more on MRI) confer poor longterm outcome independent of other risk factors, even in

FIGURE 12. Radiography or CT alone cannot determine functional disease status. Sagittal CT image (left) and corresponding fused ${ }^{18} \mathrm{~F}-\mathrm{FDG}$ PET/ CT image (right) in patient with newly diagnosed MM show that CT cannot demonstrate disease activity or optimum site for biopsy. CT reveals obvious focal osteolytic lesion at L4 and smaller one in S1, each of which is shown to be inactive on fused image. Although CT demonstrated focal bone lesions of symptomatic MM, CT-directed biopsy of focal osteolytic L4 lesion might not yield accurate diagnostic information. If functional imaging were used to direct biopsy to metabolically active disease in L5 vertebral body or L5 spinous process, yield of clinically relevant cytogenetic abnormalities would statistically be higher. (Reprinted with permission of (78).) patients with gene expression profiling identifying low-risk disease, but do not correlate with short-term response (21). EMD confers a poor prognosis, especially if present at baseline (21). The longer a patient has MM, the more likely the patient is to develop EMD and hypo- or nonsecretory disease, both high-risk entities for poorly differentiated, aggressive disease. As with malignant lymphoma, achieving a PET complete remission (normalization of ${ }^{18} \mathrm{~F}-\mathrm{FDG}$ uptake in focal bone lesions and sites of EMD) (Fig. 14) before stem cell transplantation is associated with superior durability of remission and improved survival, even in patients who are at high risk by gene expression profiling (21).

Occult infection is a significant source of morbidity and mortality for MM patients. The use of chronic high-dose glucocorticoid and pain medications and the frequent presence of tumor-related fever make detection of infection problematic. Melphalan-based myeloablation preparatory for stem cell transplantation, a mainstay of MM treatment, often results in both significant neutropenia and immunosuppression, reducing the accuracy of radiolabeled leukocyte scans to identify a site of infection. A sudden elevation of C-reactive protein is suggestive of but not specific for infection (76). In this difficult setting, ${ }^{18} \mathrm{~F}-\mathrm{FDG}$ PET/CT is superior to other imaging methods for detection of occult infection (76).

Clinically silent infections in this setting include septic thrombophlebitis of venous catheters, sinusitis, pneumonia,
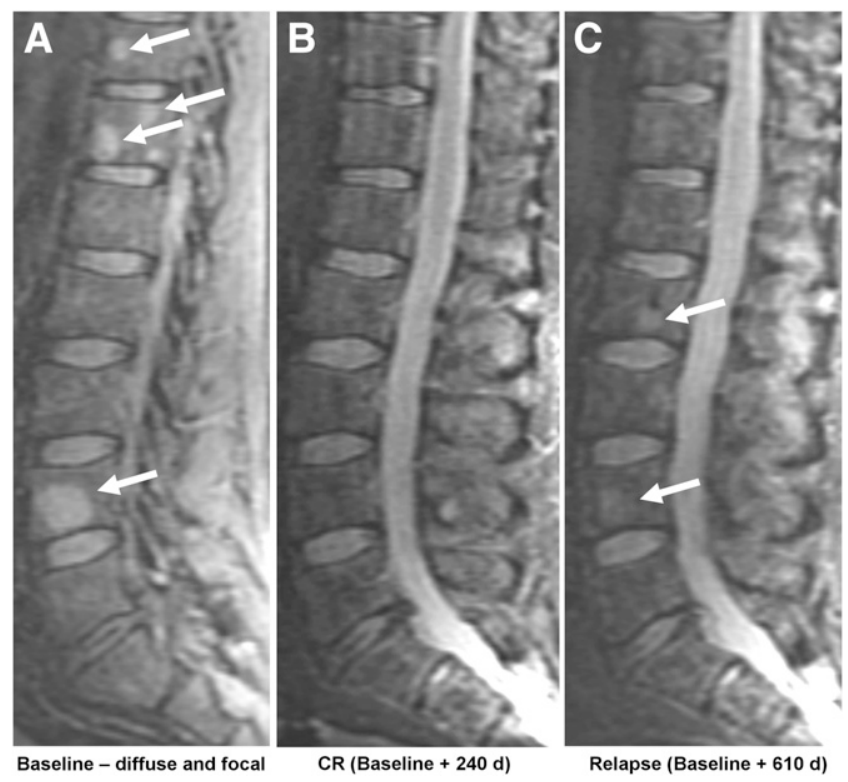

FIGURE 13. Sagittal views of short-tau inversion recoveryweighted MRI series demonstrating baseline diffuse and focal disease, treatment response, and relapse. (A) At time of diagnosis, diffuse tumor infiltration and focal lesions are seen (arrows). (B) Complete response is seen 240 d later, with normal MRI appearance. (C) Relapse is seen $610 \mathrm{~d}$ after diagnosis, with slight increase in diffuse, heterogeneous marrow signal, recurrent focal lesion at L4 (bottom arrow), and new focal lesion at L2 (top arrow). (Reprinted with permission of (10).) 


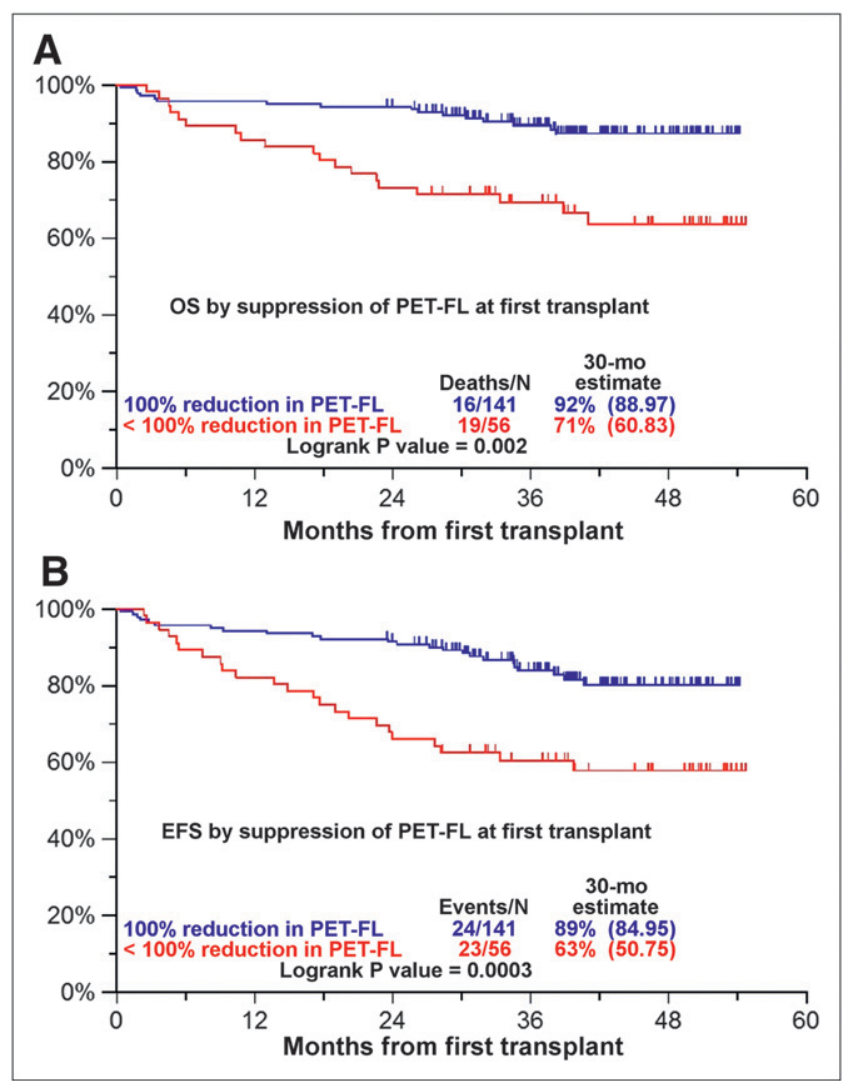

FIGURE 14. Kaplan-Meier analysis demonstrating superior overall survival (OS, A) and event-free survival (EFS, B) for patients whose baseline focal lesion (FL) or sites of EMD showed complete normalization on PET. Normalization of PET/CT scan conferred superior outcome for patients before first of two autologous stem cell transplantations in clinical trial Total Therapy 3. (Reprinted with permission of (21).)

osteomyelitis, diskitis, cellulitis, mastoiditis, and infections of the genitourinary or gastrointestinal tracts. Periodontal abscesses are frequent and must be excluded from tumor involvement or from osteonecrosis of the mandible or maxilla. Although a variety of organisms are responsible for perioral infections, fungal infection is frequently seen, often associated with osteonecrosis. ${ }^{18} \mathrm{~F}-\mathrm{FDG}$ PET/CT contributes significantly to patient management by identifying the presence and site of possible infection, establishing the extent of infection, and modifying the diagnosis or therapy $(47,50,76)$.

Patients with hematologic malignancies are at high risk for potentially life-threatening lung infections, especially within the first $100 \mathrm{~d}$ of stem cell transplantation, seen in about $7 \%$. Though multiple organisms are potential candidates (bacterial, viral, and fungal), Cytomegalovirus (37\%) and Aspergillus sp. (30\%) are the 2 most common pathogens (77).

\section{CONCLUSION}

Advanced MRI, ${ }^{18} \mathrm{~F}-\mathrm{FDG}$ PET/CT, and ${ }^{99 \mathrm{~m}} \mathrm{Tc}$-sestimibi imaging of patients with $\mathrm{MM}$ and related diseases are use- ful and reliable techniques that assist diagnosis, identify high-yield biopsy sites, and provide results superior to those of conventional imaging with MBS for staging and restaging patients, detecting EMD, and demonstrating response to treatment. Because of the wider field of view of wholebody PET/CT and SPECT/CT, their detection of EMD is superior to that of conventional MRI, though whole-body MRI may prove similar to whole-body PET/CT in this regard. MRI, PET/CT, and ${ }^{99 \mathrm{~m} T c-s e s t i m i b i}$ imaging are effective for secretory and nonsecretory disease. PET/CT and ${ }^{99 \mathrm{~m}} \mathrm{Tc}$-sestimibi imaging are superior to MRI for monitoring treatment response.

${ }^{18} \mathrm{~F}-\mathrm{FDG}$ PET/CT is especially useful in patients with hematologic malignancies for detection and localization of occult infection-even in patients with severe neutropenia-providing information that often contributes to a change in patient management.

A large number of focal lesions or the presence of EMD identifies patients who are at high risk, have poor longterm prognosis, and may benefit from aggressive monitoring and treatment. Treatment successful in achieving a PET complete response before initial stem cell transplantation confers superior overall and event-free survival. Conversely, imaging identification of disease progression on treatment identifies a patient in need of immediate intervention.

\section{REFERENCES}

1. Palumbo A, Anderson K. Multiple myeloma. N Engl J Med. 2011;364:10461060.

2. Rajkumar SV, Larson D, Kyle RA. Diagnosis of smoldering multiple myeloma. $N$ Engl J Med. 2011;365:474-475.

3. Angtuaco EJ, Fassas AB, Walker R, Sethi R, Barlogie B. Multiple myeloma: clinical review and diagnostic imaging. Radiology. 2004;231:11-23.

4. Pace L, Catalano L, Pinto A, et al. Different patterns of technetium-99m sestamibi uptake in multiple myeloma. Eur J Nucl Med. 1998;25:714-720.

5. Fonti R, Del Vecchio S, Zannetti A, et al. Bone marrow uptake of ${ }^{99 \mathrm{~m}} \mathrm{Tc}-\mathrm{MIBI}$ in patients with multiple myeloma. Eur J Nucl Med. 2001;28:214-220.

6. Chiu ML, Kronauge JF, Piwnica-Worms D. Effect of mitochondrial and plasma membrane potentials on accumulation of hexakis (2-methoxyisobutylisonitrile) technetium(I) in cultured mouse fibroblasts. J Nucl Med. 1990;31:1646-1653.

7. Tian E, Zhan F, Walker R, et al. The role of the Wnt-signaling antagonist DKK1 in the development of osteolytic lesions in multiple myeloma. $N$ Engl J Med. 2003;349:2483-2494.

8. Roodman GD. Pathogenesis of myeloma bone disease. Blood Cells Mol Dis. 2004;32:290-292.

9. Glass DA II, Patel MS, Karsenty G. A new insight into the formation of osteolytic lesions in multiple myeloma. N Engl J Med. 2003;349:2479-2480.

10. Walker R, Barlogie B, Haessler J, et al. Magnetic resonance imaging in multiple myeloma: diagnostic and clinical implications. J Clin Oncol. 2007;25:11211128 .

11. Avva R, Vanhemert RL, Barlogie B, Munshi N, Angtuaco EJ. CT-guided biopsy of focal lesions in patients with multiple myeloma may reveal new and more aggressive cytogenetic abnormalities. AJNR. 2001;22:781-785.

12. Callander NS, Roodman GD. Myeloma bone disease. Semin Hematol. 2001; 38:276-285.

13. Barlogie B, Shaughnessy J, Tricot G, et al. Treatment of multiple myeloma. Blood. 2004;103:20-32.

14. Nanni C, Rubello D, Zamagni E, et al. ${ }^{18}$ F-FDG PET/CT in myeloma with presumed solitary plasmocytoma of bone. In Vivo. 2008;22:513-517.

15. Chim CS, Ooi GC, Loong F, Liang R. Unusual presentations of hematologic malignancies: CASE 1. Solitary bone plasmacytoma: role of magnetic resonance imaging and positron emission tomography. J Clin Oncol. 2004;22: 1328-1330. 
16. Liebross RH, Ha CS, Cox JD, Weber D, Delasalle K, Alexanian R. Solitary bone plasmacytoma: outcome and prognostic factors following radiotherapy. Int J Radiat Oncol Biol Phys. 1998;41:1063-1067.

17. Moulopoulos LA, Dimopoulos MA, Weber D, Fuller L, Libshitz HI, Alexanian R. Magnetic resonance imaging in the staging of solitary plasmacytoma of bone. $J$ Clin Oncol. 1993;11:1311-1315.

18. Schirrmeister H, Buck AK, Bergmann L, Reske SN, Bommer M. Positron emission tomography (PET) for staging of solitary plasmacytoma. Cancer Biother Radiopharm. 2003;18:841-845.

19. Weber DM. Solitary bone and extramedullary plasmacytoma. Hematology (Am Soc Hematol Educ Program). 2005:373-376.

20. Soutar R, Lucraft H, Jackson G, et al. Guidelines on the diagnosis and management of solitary plasmacytoma of bone and solitary extramedullary plasmacytoma. Br J Haematol. 2004;124:717-726.

21. Bartel TB, Haessler J, Brown TL, et al. F18-fluorodeoxyglucose positron emission tomography in the context of other imaging techniques and prognostic factors in multiple myeloma. Blood. 2009;114:2068-2076.

22. Delbeke D, Coleman RE, Guiberteau MJ, et al. Procedure guideline for tumor imaging with ${ }^{18}$ F-FDG PET/CT 1.0. J Nucl Med. 2006;47:885-895.

23. Fletcher JW, Djulbegovic B, Soares HP, et al. Recommendations on the use of ${ }^{18}$ F-FDG PET in oncology. J Nucl Med. 2008;49:480-508.

24. Gerlinger M, Rowan AJ, Horswell S, et al. Intratumor heterogeneity and branched evolution revealed by multiregion sequencing. N Engl J Med. 2012; 366:883-892.

25. Longo DL. Tumor heterogeneity and personalized medicine. $N$ Engl J Med. 2012;366:956-957.

26. Shortt CP, Gleeson TG, Breen KA, et al. Whole-Body MRI versus PET in assessment of multiple myeloma disease activity. AJR. 2009;192:980986.

27. Kubota R, Yamada S, Kubota K, Ishiwata K, Tamahashi N, Ido T. Intratumoral distribution of fluorine-18-fluorodeoxyglucose in vivo: high accumulation in macrophages and granulation tissues studied by microautoradiography. $\mathrm{J} \mathrm{Nucl}$ Med. 1992;33:1972-1980.

28. Higashi K, Clavo AC, Wahl RL. In vitro assessment of 2-fluoro-2-deoxy-Dglucose, L-methionine and thymidine as agents to monitor the early response of a human adenocarcinoma cell line to radiotherapy. J Nucl Med. 1993;34:773779 .

29. Naumann R, Vaic A, Beuthien-Baumann B, et al. Prognostic value of positron emission tomography in the evaluation of post-treatment residual mass in patients with Hodgkin's disease and non-Hodgkin's lymphoma. $\mathrm{Br}$ J Haematol. 2001;115:793-800

30. Weihrauch MR, Re D, Scheidhauer K, et al. Thoracic positron emission tomography using ${ }^{18} \mathrm{~F}$-fluorodeoxyglucose for the evaluation of residual mediastinal Hodgkin disease. Blood. 2001;98:2930-2934.

31. Epstein J, Walker R. Myeloma and bone disease: "the dangerous tango." Clin Adv Hematol Oncol. 2006;4:300-306.

32. Zamagni E, Nanni C, Patriarca F, et al. A prospective comparison of ${ }^{18} \mathrm{~F}-$ fluorodeoxyglucose positron emission tomography-computed tomography, magnetic resonance imaging and whole-body planar radiographs in the assessment of bone disease in newly diagnosed multiple myeloma. Haematologica. 2007;92:50-55.

33. Fonti R, Salvatore B, Quarantelli M, et al. ${ }^{18}$ F-FDG PET/CT, ${ }^{99 \mathrm{~m} T c-M I B I}$, and MRI in evaluation of patients with multiple myeloma. J Nucl Med. 2008;49:195200.

34. Bladé J, Kyle RA. Nonsecretory myeloma, immunoglobulin D myeloma, and plasma cell leukemia. Hematol Oncol Clin North Am. 1999;13:12591272 .

35. Dispenzieri A, Kyle R, Merlini G, et al. International Myeloma Working Group guidelines for serum-free light chain analysis in multiple myeloma and related disorders. Leukemia. 2009;23:215-224.

36. Drayson M, Tang LX, Drew R, Mead GP, Carr-Smith H, Bradwell AR. Serum free light-chain measurements for identifying and monitoring patients with nonsecretory multiple myeloma. Blood. 2001;97:2900-2902.

37. Durie BG, Kyle RA, Belch A, et al. Myeloma management guidelines: a consensus report from the Scientific Advisors of the International Myeloma Foundation. Hematol J. 2003;4:379-398.

38. Orchard K, Barrington S, Buscombe J, Hilson A, Prentice HG, Mehta A. Fluorodeoxyglucose positron emission tomography imaging for the detection of occult disease in multiple myeloma. Br J Haematol. 2002;117:133-135.

39. Schirrmeister H, Bommer M, Buck AK, et al. Initial results in the assessment of multiple myeloma using ${ }^{18}$ F-FDG PET. Eur J Nucl Med Mol Imaging. 2002; 29:361-366.

40. Durie BG, Waxman AD, D'Agnolo A, Williams CM. Whole-body ${ }^{18}$ F-FDG PET identifies high-risk myeloma. J Nucl Med. 2002;43:1457-1463.
41. Dispenzieri A, Kyle RA, Lacy MQ, et al. POEMS syndrome: definitions and long-term outcome. Blood. 2003;101:2496-2506.

42. Gandhi GY, Basu R, Dispenzieri A, Basu A, Montori VM, Brennan MD. Endocrinopathy in POEMS syndrome: the Mayo Clinic experience. Mayo Clin Proc. 2007;82:836-842.

43. Dispenzieri A. POEMS syndrome. Blood Rev. 2007;21:285-299.

44. Prasad R, Yadav RR, Singh A, Mathur SP, Mangal Y, Singh M. Case report: non-secretory multiple myeloma presenting with diffuse sclerosis of affected bones interspersed with osteolytic lesions. Br J Radiol. 2009;82: e29-e31.

45. Talamo G, Angtuaco E, Walker RC, et al. Avascular necrosis of femoral and/or humeral heads in multiple myeloma: results of a prospective study of patients treated with dexamethasone-based regimens and high-dose chemotherapy. J Clin Oncol. 2005;23:5217-5223.

46. Bisdas S, Chambron Pinho N, Smolarz A, Sader R, Vogl TJ, Mack MG. Biphosphonate-induced osteonecrosis of the jaws: CT and MRI spectrum of findings in 32 patients. Clin Radiol. 2008;63:71-77.

47. Miceli MH, Jones Jackson LB, Walker RC, Talamo G, Barlogie B, Anaissie EJ. Diagnosis of infection of implantable central venous catheters by $\left[{ }^{18} \mathrm{~F}\right]$ fluorodeoxyglucose positron emission tomography. Nucl Med Commun. 2004;25:813818.

48. Miceli M, Atoui R, Thertulien R, et al. Deep septic thrombophlebitis: an unrecognized cause of relapsing bacteremia in patients with cancer. J Clin Oncol. 2004;22:1529-1531.

49. Miceli M, Atoui R, Walker R, et al. Diagnosis of deep septic thrombophlebitis in cancer patients by fluorine-18 fluorodeoxyglucose positron emission tomography scanning: a preliminary report. J Clin Oncol. 2004;22:1949-1956.

50. Mahfouz T, Miceli MH, Saghafifar F, et al. ${ }^{18} \mathrm{~F}$-fluorodeoxyglucose positron emission tomography contributes to the diagnosis and management of infections in patients with multiple myeloma: a study of 165 infectious episodes. J Clin Oncol. 2005;23:7857-7863.

51. Walker R, Jones-Jackson L, Miceli M, et al. FDG PET functional imaging in multiple myeloma: clinically important caveats, pitfalls, and pearls [abstract]. Blood. 2004;104:abstract 2473.

52. Durie BG, Salmon SE. A clinical staging system for multiple myeloma: correlation of measured myeloma cell mass with presenting clinical features, response to treatment, and survival. Cancer. 1975;36:842-854.

53. Durie BG. The role of anatomic and functional staging in myeloma: description of Durie/Salmon plus staging system. Eur J Cancer. 2006;42:1539-1543.

54. Edelstyn GA, Gillespie PJ, Grebbell FS. The radiological demonstration of osseous metastases: experimental observations. Clin Radiol. 1967;18:158162.

55. Baur-Melnyk A, Reiser M. Staging of multiple myeloma with MRI: comparison to MSCT and conventional radiography [in German]. Radiologe. 2004;44:874881.

56. Ludwig H, Fruhwald F, Tscholakoff D, Rasoul S, Neuhold A, Fritz E. Magnetic resonance imaging of the spine in multiple myeloma. Lancet. 1987;2: 364-366.

57. Fruehwald FX, Tscholakoff D, Schwaighofer B, et al. Magnetic resonance imaging of the lower vertebral column in patients with multiple myeloma. Invest Radiol. 1988;23:193-199.

58. Libshitz HI, Malthouse SR, Cunningham D, MacVicar AD, Husband JE. Multiple myeloma: appearance at MR imaging. Radiology. 1992;182:833837.

59. Moulopoulos LA, Varma DG, Dimopoulos MA, et al. Multiple myeloma: spinal MR imaging in patients with untreated newly diagnosed disease. Radiology. 1992;185:833-840.

60. Rahmouni A, Divine M, Mathieu D, et al. Detection of multiple myeloma involving the spine: efficacy of fat-suppression and contrast-enhanced MR imaging. AJR. 1993;160:1049-1052.

61. Moulopoulos LA, Dimopoulos MA, Smith TL, et al. Prognostic significance of magnetic resonance imaging in patients with asymptomatic multiple myeloma. J Clin Oncol. 1995;13:251-256.

62. Dimopoulos MA, Moulopoulos LA, Datseris I, et al. Imaging of myeloma bone disease: implications for staging, prognosis and follow-up. Acta Oncol. 2000;39:823-827.

63. Tertti R, Alanen A, Remes K. The value of magnetic resonance imaging in screening myeloma lesions of the lumbar spine. Br J Haematol. 1995;91:658660.

64. Van de Berg BC, Lecouvet FE, Michaux L, et al. Stage I multiple myeloma: value of MR imaging of the bone marrow in the determination of prognosis. Radiology. 1996;201:243-246.

65. Scherer A, Wittsack HJ, Strupp C, Gattermann N, Haas R, Modder U. Vertebral fractures in multiple myeloma: first results of assessment of fracture risk using 
dynamic contrast-enhanced magnetic resonance imaging. Ann Hematol. 2002; 81:517-521.

66. Garcia-Ferrer L, Bagan JV, Martinez-Sanjuan V, et al. MRI of mandibular osteonecrosis secondary to bisphosphonates. AJR. 2008;190:949-955.

67. Agarwal R, Brunelli SM, Williams K, Mitchell MD, Feldman HI, Umscheid CA. Gadolinium-based contrast agents and nephrogenic systemic fibrosis: a systematic review and meta-analysis. Nephrol Dial Transplant. 2009;24:856863.

68. Chrysochou C, Buckley DL, Dark P, Cowie A, Kalra PA. Gadolinium-enhanced magnetic resonance imaging for renovascular disease and nephrogenic systemic fibrosis: critical review of the literature and UK experience. J Magn Reson Imaging. 2009;29:887-894.

69. Weininger M, Lauterbach B, Knop S, et al. Whole-body MRI of multiple myeloma: comparison of different MRI sequences in assessment of different growth patterns. Eur J Radiol. 2009;69:339-345.

70. Baur-Melnyk A, Buhmann S, Becker C, et al. Whole-body MRI versus whole-body MDCT for staging of multiple myeloma. AJR. 2008;190:10971104 .

71. Schmidt GP, Reiser MF, Baur-Melnyk A. Whole-body MRI for the staging and follow-up of patients with metastasis. Eur J Radiol. 2009;70:393-400.
72. el-Shirbiny AM, Yeung H, Imbriaco M, Michaeli J, Macapinlac H, Larson SM. Technetium-99m-MIBI versus fluorine-18-FDG in diffuse multiple myeloma. J Nucl Med. 1997;38:1208-1210.

73. Blocklet D, Schoutens A, Kentos A, Feremans W. Bone marrow uptake of ${ }^{99 \mathrm{~m}}$ Tc-MIBI in patients with multiple myeloma. Eur J Nucl Med. 2001;28: 1430-1432.

74. Giovanella L, Taborelli M, Ceriani L, Zucca E, Cavalli F, Delaloye AB. ${ }^{99 m}$ Tcsestamibi imaging and bone marrow karyotyping in the assessment of multiple myeloma and MGUS. Nucl Med Commun. 2008;29:535-541.

75. Zhan F, Huang Y, Colla S, et al. The molecular classification of multiple myeloma. Blood. 2006;108:2020-2028.

76. Walker RC, Jones-Jackson LB, Martin W, Habibian MR, Delbeke D. New imaging tools for the diagnosis of infection. Future Microbiol. 2007;2:527-554.

77. Leung AN, Gosselin MV, Napper $\mathrm{CH}$, et al. Pulmonary infections after bone marrow transplantation: clinical and radiographic findings. Radiology. 1999;210:699-710.

78. Walker R, Jones-Jackson L, Bartel T, Brown T, Barlogie B. Imaging of multiple myeloma, solitary plasmacytoma, MGUS, and other plasma cell dyscrasias In: Roodman GD, ed. Myeloma Bone Disease. New York, NY: Humana Press; 2010:15-62 